\title{
Respiratory symptoms in relation to residential coal burning and environmental tobacco smoke among early adolescents in Wuhan, China: a cross-sectional study
}

\author{
Päivi M Salo1, Jiang Xia ${ }^{2}$, C Anderson Johnson ${ }^{3}$, Yan $\mathrm{Li}^{4}$, Grace E Kissling5, \\ Edward L Avol ${ }^{6}$, Chunhong Liu ${ }^{2}$ and Stephanie J London*1
}

Address: ${ }^{2}$ Epidemiology Branch, National Institute of Environmental Health Sciences, National Institutes of Health, MD A3-05, PO Box 12233, Research Triangle Park, NC 27709, USA, ${ }^{2}$ Wuhan Public Health and Anti-Epidemic Station, No. 24 N. Jianghan Road, Wuhan, Hubei 430022, China, ${ }^{3}$ Institute for Health Promotion \& Disease Prevention Research, USC Keck School of Medicine, 1000 South Fremont Ave., Unit 8, Alhambra, CA 91803, USA, ${ }^{4}$ Wuhan Health Bureau, 2 YiYuan Road, Wuhan, Hubei 430014, China, ${ }^{5}$ Biostatistics Branch, National Institute of Environmental Health Sciences, National Institutes of Health, MD A3-03, PO Box 12233, Research Triangle Park, NC 27709, USA and ${ }^{6}$ Department of Occupational \& Environmental Health, USC Keck School of Medicine, CHP 236, 1540 Alcazar St., Los Angeles, CA 90089, USA

Email: Päivi M Salo - salo1@niehs.nih.gov; Jiang Xia - xiajiang@public.wh.hb.cn; C Anderson Johnson - carljohn@hsc.usc.edu; Yan Li - yanli@public.wh.hb.cn; Grace E Kissling - kissling@niehs.nih.gov; Edward L Avol - avol@hsc.usc.edu; Chunhong Liu - liups@public.wh.hb.cn; Stephanie J London* - london2@niehs.nih.gov

* Corresponding author

Published: 07 December 2004

Environmental Health: A Global Access Science Source 2004, 3:14 doi:10.1 186/1476-069X-3-14

This article is available from: http://www.ehjournal.net/content/3/I/I4

(c) 2004 Salo et al; licensee BioMed Central Ltd.

This is an Open Access article distributed under the terms of the Creative Commons Attribution License (http://creativecommons.org/licenses/by/2.0), which permits unrestricted use, distribution, and reproduction in any medium, provided the original work is properly cited.

\begin{abstract}
Background: Cigarette smoking and coal burning are the primary sources of indoor air pollution in Chinese households. However, effects of these exposures on Chinese children's respiratory health are not well characterized.
\end{abstract}

Methods: Seventh grade students $(N=505 \mathrm{I})$ from 22 randomly selected schools in the greater metropolitan area of Wuhan, China, completed an in-class self-administered questionnaire on their respiratory health and home environment.

Results: Coal burning for cooking and/or heating increased odds of wheezing with colds [odds ratio $(\mathrm{OR})=1.57,95 \%$ confidence interval $(\mathrm{Cl}): 1.07-2.29]$ and without colds $(\mathrm{OR}=1.44,95 \% \mathrm{Cl}$ : I.05-1.97). For smoking in the home, the strongest associations were seen for cough $(O R=1.74$, $95 \% \mathrm{Cl}$ : I. $17-2.60)$ and phlegm production $(\mathrm{OR}=2.25,95 \% \mathrm{Cl}$ : I.36-3.72) without colds among children who lived with two or more smokers.

Conclusions: Chinese children living with smokers or in coal-burning homes are at increased risk for respiratory impairment. While economic development in China may decrease coal burning by providing cleaner fuels for household energy use, the increasing prevalence of cigarette smoking is a growing public health concern due to its effects on children. Adverse effects of tobacco smoke exposure were seen despite the low rates of maternal smoking $(3.6 \%)$ in this population. 


\section{Background}

Residential coal burning and cigarette smoking are the most common sources of indoor air pollution in Chinese households [1-3]. Although use of coal stoves and smoking have been linked to respiratory morbidity among adult populations in mainland China [1,4-6], little is known about how these exposures affect Chinese children's respiratory health. Children's developing lungs are especially vulnerable to indoor air pollution because children spend much of their time indoors at home $[7,8]$.

Coal has been widely used for cooking and heating in China $[1,9]$. Domestic coal stoves and boilers produce high indoor concentrations of sulfur dioxide $\left(\mathrm{SO}_{2}\right)$, carbon monoxide $(\mathrm{CO})$, particulate matter, and other pollutants $[2,3,10,11]$. Some studies suggest that indoor concentrations of emitted pollutants may exceed international guidelines and national ambient air pollution standards in China $[1,2]$.

An increasing proportion of Chinese children are exposed to tobacco smoke because smoking prevalence in China has increased rapidly, especially among men, during the last decades $[1,12]$. Over two thirds of the Chinese population is currently exposed to environmental tobacco smoke (ETS) in the home [12]. Literature from Western populations has generally shown that maternal smoking is more strongly associated with children's respiratory symptoms than paternal smoking $[13,14]$. China provides a unique opportunity to examine effects of parental smoking because prevalence of smoking remains very low among women.

We examined the associations between respiratory symptoms and exposure to residential coal burning and environmental tobacco smoke in a cross-sectional study of seventh grade students in the greater metropolitan area of Wuhan, China.

\section{Methods}

\section{Participants and study procedure}

In the spring of 1999, 5231 seventh grade students at 22 public schools in and around Wuhan, China were invited to complete a self-administered questionnaire on respiratory symptoms and home environment. Two schools were randomly selected from each of the 11 administrative units governed by the city of Wuhan, the capital of Hubei Province. The resulting schools included 14 schools from urban (53.0\% of the students), three schools from suburban $(25.1 \%)$, and five schools from rural areas (21.9\%). Of the 5231 students, 5051 (97\%) provided parental consent and completed the questionnaire in class with study staff in attendance. Before completing the questions students viewed a video demonstrating wheezing [15]. The study protocol was approved by the Institutional Review
Boards at the Wuhan Public Health and Anti-Epidemic Station and the National Institute of Environmental Health Sciences.

\section{Questionnaire data}

The questionnaire included questions on respiratory health and potential risk factors such as exposure to cooking and heating fuels, smokers in the home, and personal smoking. We incorporated respiratory health items from a standardized questionnaire (ATS-DLD-78-C) translated into Chinese for a previous study in Wuhan and other Chinese cities [16]. Our primary outcome measures were responses to questions regarding respiratory symptoms in the past 12 months. We asked whether children had cough and/or phlegm production almost everyday during the past 12 months, with and without colds. Additionally, we asked whether children had wheezing over the past 12 months, with and without colds.

We assessed exposure to residential coal burning by questions defining the types of fuels used for cooking and heating in the child's home. We combined information on cooking and heating with coal into a single variable with the following categories: no coal stove, coal stove used only for heating, coal stove used only for cooking, and coal stove used for both cooking and heating. To assess environmental tobacco smoke exposure, we asked the child to list all household members and indicate whether each person currently smoked. We created three exposure categories: no smokers in the home, one smoker (1) in the home, and two or more smokers $(2+)$ in the home. Personal smoking was not considered in the analysis because of very low prevalence $(0.6 \%)$.

\section{Statistical analysis}

We calculated prevalence odds ratios (95\% confidence intervals) for each of the six outcome measures (cough, phlegm production and wheezing in the past 12 months, each with colds and without colds) by unconditional logistic regression (Proc Genmod in SAS System for Windows, Version 8.01). Although the odds ratio is the most common measure of association in cross-sectional studies [17], divergence between odds ratios and risk ratios increases as the outcome becomes more common $[18,19]$. However, we present odds ratios as our effect measures to estimate the associations between respiratory symptoms and residential exposures (coal burning and environmental tobacco smoke); using the log-binomial model (Proc Genmod in SAS System for Windows, Version 8.01) [20] to estimate prevalence proportion ratios for the outcomes did not alter any of our conclusions.

We excluded 521 subjects with missing data on any of the outcome or exposure variables leaving 4,530 subjects for the analysis. The following covariates were considered as 
potential confounders or modifying factors within the logistic models: child's gender, presence of animals in the household, presence of pests (cockroaches, ants, rodents), crowding in the household, presence of older siblings, parental asthma, physical activity, living area (school district), and time spent indoors and outdoors. To account for variation due to the type of neighborhood the children lived in, we included school district (22 districts) in the models using CLASS and REPEATED statements within Proc Genmod in SAS. The models reported here are adjusted for coal use, smokers in the home, school district, and child's sex because inclusion of the other variables did not appreciably change the associations.

\section{Results}

Characteristics of the study population are presented in Table 1 . The mean age of the seventh grade students was 13.6 years ( $\mathrm{SD}=0.7$ years). The majority of the students $(94.2 \%)$ were life-long residents of the Wuhan area. Although $7.1 \%$ of the students reported wheezing without colds, doctor-diagnosed asthma was relatively uncommon in this population (3.2\%). Coal was used for cooking and/or heating in almost half of the homes. Few

Table I: Characteristics of the study population of 4530 students at 22 schools in greater Wuhan, China

\begin{tabular}{lr}
\hline Characteristic & $\%$ \\
\hline Subjects & \\
Age (mean, SD) in years & $13.6,0.7$ \\
Gender & \\
$\quad$ Male & 52.5 \\
Female & 47.5 \\
& \\
Respiratory symptoms & \\
Wheezing with colds & 19.4 \\
Wheezing without colds & 7.1 \\
Bringing up phlegm with colds & 16.7 \\
Bringing up phlegm without colds & 5.7 \\
Coughing with colds & 24.7 \\
Coughing without colds & 4.5 \\
& \\
Exposures & \\
Smokers in child's household & \\
No smokers & 26.8 \\
I smoker & 62.3 \\
2+ smokers & 10.9 \\
Father smokes & 69.1 \\
Mother smokes & 3.6 \\
Personal smoking by students & 0.6 \\
Exposure to coal burning & \\
No coal use & \\
Coal used only for heating & \\
Coal used only for cooking & \\
Coal used for cooking and & 11.8 \\
heating & \\
\end{tabular}

children smoked $(0.6 \%)$, but $73.2 \%$ of the students lived with household members who smoked. The prevalence of ETS exposure was similar across the study area $(74.5 \%$ in urban areas, $70.2 \%$ in suburban areas, and $73.5 \%$ in rural areas). Fathers $(69.1 \%)$ were much more likely to smoke than mothers $(3.6 \%)$.

After adjusting for gender, ETS, and living area, residential coal burning was primarily associated with wheezing in the past 12 months (Table 2). For those who used coal only for cooking or only for heating, wheezing was more strongly associated with cooking. However, the association between coal use and recent wheezing tended to strengthen when coal was used for both cooking and heating $(\mathrm{OR}=1.78,95 \% \mathrm{CI}: 1.08-2.91$ for wheezing with colds; $\mathrm{OR}=1.57,95 \% \mathrm{CI}$ : $0.94-2.64$ for wheezing without colds).

After adjusting for gender, coal use, and living area, living with smokers (Table 3 ) was significantly associated with chronic cough and phlegm production in the past 12 months. The strongest associations were seen for cough $(\mathrm{OR}=1.74,95 \% \mathrm{CI}: 1.17-2.60)$ and phlegm production $(\mathrm{OR}=2.25,95 \% \mathrm{CI}: 1.36-3.72)$ without colds among children who lived with two or more smokers. Living with smokers was not appreciably associated with wheezing.

\section{Discussion}

Domestic coal use and exposure to ETS in the home were both associated with adverse respiratory effects in this population of Chinese adolescents. Coal burning was associated with increased wheezing, whereas living with smokers was associated with increased cough and phlegm production.

Coal burning produces high concentrations of particulate matter, $\mathrm{SO}_{2}$, and other pollutants $[2,3,11]$. Exposure to these pollutants may impair clearance mechanisms, and lead to airway inflammation $[21,22]$. Decreased pulmonary function has been associated with exposure to particulate matter and $\mathrm{SO}_{2}$ in several air pollution studies during the past decades [21]. Although residential coal burning has been linked to decreased pulmonary function and asthma among children [23-25], conflicting data exist. In two European studies, domestic coal burning has been associated with lower risk for childhood asthma and allergic diseases $[26,27]$. The findings in these two studies, however, may reflect some early life or other lifestyle factors related to coal use in Europe.

In our study, residential coal burning was predominantly associated with wheezing. Coal cooking was a stronger risk factor for wheezing than was coal heating. This may be explained by relatively low heating use in the Wuhan area, whereas cooking is a year around activity. The greater 
Table 2: Respiratory symptoms in relation to residential coal burning

\begin{tabular}{|c|c|c|c|c|c|c|c|c|}
\hline \multirow[b]{3}{*}{ Exposure } & \multicolumn{4}{|c|}{ Cough with colds } & \multicolumn{4}{|c|}{ Cough without colds } \\
\hline & No & Yes & & & No & Yes & & \\
\hline & $\mathrm{N}$ & $\mathrm{N}$ & $\mathrm{OR}^{*}$ & $(95 \% \mathrm{Cl})$ & $\mathrm{N}$ & $\mathrm{N}$ & OR* & $(95 \% \mathrm{Cl})$ \\
\hline Total & 3413 & 1117 & & & 4327 & 203 & & \\
\hline \multicolumn{9}{|l|}{ Coal use } \\
\hline No & 1833 & 622 & 1.00 & & 2347 & 108 & 1.00 & \\
\hline Yes & 1580 & 495 & 0.92 & $(0.76, I . I I)$ & 1980 & 95 & 1.03 & $(0.80,1.33)$ \\
\hline Heating & 300 & 99 & 0.96 & $(0.76,1.22)$ & 381 & 18 & 1.02 & $(0.67,1.55)$ \\
\hline Cooking & 926 & 249 & 0.79 & $(0.67,0.94)$ & 1120 & 55 & 1.04 & $(0.74,1.46)$ \\
\hline \multirow[t]{4}{*}{ Both } & 354 & 147 & 1.22 & $(0.93,1.59)$ & 479 & 22 & 0.99 & $(0.66,1.49)$ \\
\hline & \multicolumn{4}{|c|}{ Phlegm with colds } & \multicolumn{3}{|c|}{ Phlegm without colds } & \\
\hline & No & Yes & & & No & Yes & & \\
\hline & $\mathrm{N}$ & $\mathrm{N}$ & OR* & $(95 \% \mathrm{Cl})$ & $\mathrm{N}$ & $\mathrm{N}$ & OR* & $(95 \% \mathrm{Cl})$ \\
\hline Total & 3772 & 758 & & & 4274 & 256 & & \\
\hline \multicolumn{9}{|l|}{ Coal use } \\
\hline No & 2051 & 404 & 1.00 & & 2315 & 140 & 1.00 & \\
\hline Yes & $172 \mid$ & 354 & 1.04 & $(0.90,1.20)$ & 1959 & 116 & 0.96 & $(0.75,1.23)$ \\
\hline Heating & 331 & 68 & 1.04 & $(0.86,1.27)$ & 376 & 23 & 1.02 & $(0.62,1.66)$ \\
\hline Cooking & 994 & 181 & 0.92 & $(0.76,1.10)$ & 1114 & 61 & 0.86 & $(0.64,1.16)$ \\
\hline \multirow[t]{4}{*}{ Both } & 396 & 105 & 1.34 & $(1.05,1.73)$ & 469 & 32 & 1.12 & $(0.81,1.54)$ \\
\hline & \multicolumn{4}{|c|}{ Wheeze with colds } & \multicolumn{4}{|c|}{ Wheeze without colds } \\
\hline & No & Yes & & & No & Yes & & \\
\hline & $\mathrm{N}$ & $\mathrm{N}$ & $\mathrm{OR}^{*}$ & $(95 \% \mathrm{Cl})$ & $\mathrm{N}$ & $\mathrm{N}$ & OR* & $(95 \% \mathrm{Cl})$ \\
\hline Total & 3652 & 878 & & & 4210 & 320 & & \\
\hline \multicolumn{9}{|l|}{ Coal use } \\
\hline No & 2058 & 397 & 1.00 & & 2309 & 146 & 1.00 & \\
\hline Yes & 1594 & 481 & 1.57 & $(1.07,2.29)$ & 1901 & 174 & 1.44 & $(1.05,1.97)$ \\
\hline Heating & 329 & 70 & 1.10 & $(0.76,1.57)$ & 368 & 31 & 1.35 & $(0.86,2.15)$ \\
\hline Cooking & 892 & 283 & 1.66 & $(1.01,2.73)$ & 1077 & 98 & 1.42 & $(1.05,1.92)$ \\
\hline Both & 373 & 128 & 1.78 & $(1.08,2.91)$ & 456 & 45 & 1.57 & $(0.94,2.64)$ \\
\hline
\end{tabular}

* Odds ratios (OR) adjusted for gender, ETS, and school district. Dichotomous and multilevel odds ratios are computed in separate models.

association with coal use for both cooking and heating may suggest an exposure-dependent relationship.

Although wheezing is often closely related to asthma, coal use was not positively associated with asthma diagnosis (data not shown) in this population. The majority of the diagnosed asthmatics (76.4\%) lived in urban areas, where prevalence of coal use was lower than in non-urban areas. The diagnostic ascertainment of asthma most likely was greater in the urban than in the rural areas.

The harmful effects of ETS in children, primarily from living with smokers, have been widely studied [14,28-31]. In general, evidence that ETS causes cough, phlegm, and wheezing has not been as strong for school-aged children as it has been for infants and preschool children [28]. There are few data among Chinese populations where smoking behavior differs from Western populations. In utero exposure, via maternal smoking, that is believed to contribute to adverse effects of ETS in children [32,33] is uncommon in China. Thus, it is of interest that in this group of middle school children, where maternal and personal smoking were low, exposure to ETS in the home was clearly associated with chronic cough and phlegm production, with and without colds.

Our results indicated an exposure dependent response to ETS; having two or more smokers in the household increased the odds of cough and phlegm production compared to having only one smoker in the household. We did not find strong evidence suggesting modifying effects by gender, although the effect of ETS on persistent cough without colds was more pronounced among boys than girls (data not shown). Exposure levels may be influenced 
Table 3: Respiratory symptoms in relation to living with smokers

\begin{tabular}{|c|c|c|c|c|c|c|c|c|}
\hline \multirow[b]{3}{*}{ Exposure } & \multicolumn{4}{|c|}{ Cough with colds } & \multicolumn{4}{|c|}{ Cough without colds } \\
\hline & \multirow{2}{*}{$\frac{\text { No }}{N}$} & \multicolumn{3}{|l|}{ Yes } & \multirow{2}{*}{$\begin{array}{l}\text { No } \\
\mathrm{N}\end{array}$} & \multicolumn{3}{|l|}{ Yes } \\
\hline & & $\mathrm{N}$ & OR* & $(95 \% \mathrm{Cl})$ & & $\mathrm{N}$ & OR* & $(95 \% \mathrm{Cl})$ \\
\hline Total & 3413 & 1117 & & & 4327 & 203 & & \\
\hline \multicolumn{9}{|c|}{ Smokers in the home } \\
\hline No & 954 & 259 & 1.00 & & 1165 & 48 & 1.00 & \\
\hline Yes & 2459 & 858 & 1.29 & $(1.05,1.58)$ & 3162 & 155 & 1.19 & $(0.86,1.65)$ \\
\hline I smoker & 2105 & 717 & 1.26 & $(1.02,1.55)$ & 2700 & 122 & 1.10 & $(0.77,1.57)$ \\
\hline \multirow[t]{4}{*}{$2+$ smokers } & 354 & 141 & 1.47 & $(1.11,1.95)$ & 462 & 33 & 1.74 & $(1.17,2.60)$ \\
\hline & \multicolumn{2}{|c|}{ Phlegm with colds } & \multicolumn{6}{|c|}{ Phlegm without colds } \\
\hline & No & Yes & & & No & Yes & & \\
\hline & $\mathrm{N}$ & $\mathrm{N}$ & $\mathrm{OR}^{*}$ & $(95 \% \mathrm{Cl})$ & $\mathrm{N}$ & $\mathrm{N}$ & OR* & $(95 \% \mathrm{Cl})$ \\
\hline Total & 3772 & 758 & & & 4274 & 256 & & \\
\hline \multicolumn{9}{|c|}{ Smokers in the home } \\
\hline No & 1036 & 177 & 1.00 & & 1164 & 49 & 1.00 & \\
\hline Yes & 2736 & 581 & 1.24 & $(1.08,1.43)$ & 3110 & 207 & 1.60 & $(1.11,2.29)$ \\
\hline I smoker & 2327 & 495 & 1.25 & $(1.09,1.43)$ & 2657 & 165 & 1.49 & $(1.04,2.14)$ \\
\hline \multirow[t]{4}{*}{$2+$ smokers } & 409 & 86 & 1.23 & $(0.92,1.64)$ & 453 & 42 & 2.25 & $(1.36,3.72)$ \\
\hline & \multicolumn{2}{|c|}{ Wheeze with colds } & \multicolumn{6}{|c|}{ Wheeze without colds } \\
\hline & No & Yes & & & No & Yes & & \\
\hline & $\mathrm{N}$ & $\mathrm{N}$ & OR* & $(95 \% \mathrm{Cl})$ & $\mathrm{N}$ & $\mathrm{N}$ & OR* & $(95 \% \mathrm{Cl})$ \\
\hline Total & 3652 & 878 & & & 4210 & 320 & & \\
\hline \multicolumn{9}{|c|}{ Smokers in the home } \\
\hline No & 993 & 220 & 1.00 & & 1125 & 88 & 1.00 & \\
\hline Yes & 2659 & 658 & 1.11 & $(0.93,1.31)$ & 3085 & 232 & 0.96 & $(0.74, I .25)$ \\
\hline I smoker & 2265 & 557 & 1.10 & $(0.93,1.30)$ & 2619 & 203 & 0.99 & $(0.75,1.30)$ \\
\hline $2+$ smokers & 394 & 101 & 1.13 & $(0.85,1.49)$ & 466 & 29 & 0.78 & $(0.45,1.37)$ \\
\hline
\end{tabular}

* Odds ratios (OR) adjusted for gender, coal use, and school district. Dichotomous and multilevel odds ratios are computed in separate models.

by time-activity patterns that can differ by gender. Boys may be more likely to spend time in close proximity with their smoking fathers or male relatives than girls.

Mechanisms responsible for the respiratory effects of ETS have been proposed in the literature [28]. In addition to decreased mucociliary clearance and goblet cell hypertrophy/hypersecretion, local and central nervous system components are thought be involved in cough and phlegm production $[28,34]$. Although exposure to ETS may affect childhood lung growth and result in lower pulmonary function $[14,35]$, wheezing was not appreciably related to the presence of smokers in our study. Genetic susceptibility may influence the effects of ETS on bronchial obstruction. For example, parental atopy was found to modify the effects of ETS on bronchial obstruction and asthma considerably in a Norwegian birth cohort study
[36]. However, we were unable to examine potential interactions between family history and ETS in relation to atopic illness in our population because, consistent with previously published data on Chinese children $[37,38]$, the prevalence of asthma (3.2\%) and hay fever (1.8\%) was very low.

In general, our findings agree with available data on Chinese children's respiratory health $[16,23]$. However, residential exposures in the current study were more selectively associated with the respiratory symptoms than in previous studies. This may reflect differences in the study settings. In the previous studies $[16,23]$, for example, most of the children were younger in age than in the current study. Prevalence of symptoms and factors associated with childhood respiratory symptoms may differ between different age groups [39]. It is also possible that 
using students rather than parents as a source of information on child's symptoms may contribute to the observed differences.

Exposure to indoor air pollutants is not only influenced by the source strength and other emission characteristics, but also by air exchange rates. A recent study showed that ventilation could modify effects between respiratory health outcomes and indoor air pollutants [40]. In that study, the modifying effects were found most relevant when air exchange rates were low. Residences in Wuhan, however, were not energy-efficiently built [16]. Air conditioning was uncommon, and most of the homes, both in urban and non-urban areas, relied on natural ventilation. In this study, we were unable to evaluate the effects of ventilation rates, because we did not collect detailed information on ventilation practices. We thought that children would not be able to give this information accurately.

The composition of pollutants produced by residential coal burning and smoking can be highly variable, but both exposures contribute substantially to inhalable and respirable particulate matter in indoor environments $[2,3,41]$. Existing data suggests that coal burning and smoking may have synergistic effects on respiratory symptoms [5]. In our data, we did not find consistent evidence of interaction between coal burning and ETS exposure.

Our outcome and exposure measures were determined by questionnaire alone, which is one of the major limitations of the study. Nonetheless, large epidemiological studies of respiratory health often rely on reports on recent symptom history because self-reported measures are cost efficient, practical and their repeatability is good $[42,43]$. Generally, respiratory symptoms have been reported consistently across populations [43]. To improve the quality of our self-reported outcomes we included audiovisual presentation of wheezing symptoms [15]. Because the temporal relationship between outcome(s) and exposure(s) can be difficult to determine in cross-sectional studies we focused on respiratory symptoms in the past 12 months to minimize recall bias. We did not use parents as source of information on child's symptoms. Some studies suggest that Chinese parents may deny or underreport child's symptoms or illnesses $[44,45]$. In addition, parents living in non-urban areas around Wuhan have lower educational level than parents living in urban areas [16], and their literacy level may be lower than their children attending middle school. Therefore, adolescents' reports on their own symptoms and health status may be more accurate than their parents'. Because children were answering in school about exposures in their home, we were not able to acquire very detailed information on exposure characteristics. Given that questionnaires have limited ability to quantify exposures, the possibility of exposure misclassification cannot be excluded. However, serious differential misclassification either of the exposures or outcomes is unlikely because health hazards of indoor air pollutants were not widely known among Chinese school children at the time when the survey was conducted [46].

Although urban air pollution has long been a major environmental concern in China, we do not believe that outdoor air pollution alone could explain the observed associations. Exposures to indoor air pollutants are likely to dominate the total exposure burden [47], especially among children, who spend much of their time inside the home [8]. In Chinese homes with coal stoves and smokers, not only levels of particulate matter, but also levels of many other air pollutants, including concentrations of $\mathrm{SO}_{2}$, often exceed the levels outdoors [2,3]. In Wuhan, where coal stoves are not usually vented via flue, concentrations of respirable particulate matter $\left(291 \mu \mathrm{g} / \mathrm{m}^{3}\right)$ and $\mathrm{SO}_{2}\left(173 \mu \mathrm{g} / \mathrm{m}^{3}\right)$ can reach high levels indoors [2]. Concentrations of these pollutants have been found to be lower in ambient air. For example, a study investigating long-term air pollution in Wuhan estimated that the annual means for $\mathrm{PM}_{2.5}, \mathrm{PM}_{10}$, and $\mathrm{SO}_{2}$ in urban areas were $73 \mu \mathrm{g} / \mathrm{m}^{3}, 129 \mu \mathrm{g} / \mathrm{m}^{3}$, and $73 \mu \mathrm{g} / \mathrm{m}^{3}$, respectively [48]. Because indoor air quality is influenced by infiltration of outdoor air, we cannot fully exclude possible confounding effects of ambient air pollution [1]. However, the effects of living area, as measured by school districts, were taken into account in our models, providing some control for differing air pollution levels in the study area.

The major strength of this study is that the public school system ensured a large and representative sample of rural, suburban, and urban populations in the Wuhan area. Our study is one of the few studies that have examined effects of major indoor pollutants in relation to children's respiratory health in mainland China [16,23-25].

\section{Conclusions}

Coal burning and living with smokers contributed to persistent respiratory symptoms in this cohort of Chinese adolescents. Adverse effects of tobacco smoke in the home were seen despite the very low prevalence of maternal smoking. Even if exposure to residential coal burning declines in response to economic changes in China, the increasing prevalence in smoking augur an increase in children's exposure to environmental tobacco smoke. Because many men initiate smoking during adulthood, and the rate of quitting and desire to quit smoking are low [49], future prospects for children's health are worrisome. The rise in cigarette smoking in China is a growing public health concern, not only in the adult population but because its effects on children. Although rates of childhood asthma have remained low in China, common 
indoor air pollutants, coal and tobacco smoke, impair children's respiratory health.

$$
\begin{aligned}
& \text { List of abbreviations } \\
& \mathrm{CI}=\text { confidence interval } \\
& \mathrm{CO}=\text { carbon monoxide } \\
& \mathrm{ETS}=\text { environmental tobacco smoke } \\
& \mathrm{OR}=\text { odds ratio }
\end{aligned}
$$

$\mathrm{PM}_{10}=$ particulate matter with an aerodynamic diameter less or equal to $10 \mu \mathrm{m}$

$\mathrm{PM}_{2.5}=$ particulate matter with an aerodynamic diameter less or equal to $2.5 \mu \mathrm{m}$

$\mathrm{SO}_{2}=$ sulfur dioxide

\section{Competing interests}

The authors declare that they have no competing interests.

\section{Authors' contributions}

Contributors: PMS analyzed the data and wrote the manuscript with input from all investigators. YL, JX and CL are key investigators for the data collection. ELA assisted with data collection, and GK assisted with data analysis. CAJ was involved in design of the study. SJL is the principal investigator and guarantor of the manuscript.

\section{Acknowledgements}

This study was supported by the National Cancer Institute / National Institute of Drug Abuse Transdisciplinary Tobacco Use research Center grant (I P50 CA84735-0 I) awarded to the University of Southern California and the project ZOI ES 49019 of the Division of Intramural Research, National Institute of Environmental Health Sciences.

We wish to acknowledge the contribution of the Wuhan Education Committee and the Wuhan Public Health and Anti-Epidemic Station for their assistance with data collection and entry, and Ms. Gong Jie for her help with data management. We thank Dr. Chris Lai from The Chinese University of Hong Kong, China, for sharing questionnaire materials, and Dr. Grace Chiu from Westat Inc, Research Triangle Park, NC, for assistance with programming.

\section{References}

I. Florig HK: China's Air Pollution Risks. Environ Sci Technol 1997, 31:274-279.

2. Qin YH, Zhang XM, Jin HZ, Liu YQ, Fan DL, Yin XR, Li Z, Fang W, Wang GF: Indoor air pollution in four cities in China. Biomed Environ Sci 1991, 4:366-372.

3. Wang JN, Zhang Y: CO and particle pollution of indoor air in Beijing and its elemental analysis. Biomed Environ Sci 1990, 3:132-138

4. Du YX, Cha Q, Chen XW, Chen YZ, Huang LF, Feng ZZ, Wu XF, Wu JM: An epidemiological study of risk factors for lung cancer in Guangzhou, China. Lung Cancer 1996, 14 Suppl I:S9-37.

5. Pope CA, Xu X: Passive cigarette smoke, coal heating, and respiratory symptoms of nonsmoking women in China. Environ Health Perspect 1993, 101:314-316.
6. $\mathrm{Xu} X$, Wang $\mathrm{L}$ : Association of indoor and outdoor particulate level with chronic respiratory illness. Am Rev Respir Dis 1993, 148:1516-1522.

7. Silvers A, Florence BT, Rourke DL, Lorimor RJ: How children spend their time: a sample survey for use in exposure and risk assessments. Risk Anal 1994, 14:931-944.

8. Xu Y, Cuie $\mathrm{S}$, Ji X, Hanping W: Effects of indoor pollution on pulmonary function and COHb of school pupils in Wuhan city (China). Proceedings of the 6th International Conference on Indoor Air Quality and Climate. July 4-8 1993; Helsinki, Finland 1993:505-5 I0.

9. Indoor Air Pollution Database for China [http://whqlib doc.who.int/hq//995/WHO EHG 95.8.pdf]

10. Finkelman RB, Belkin HE, Zheng B: Health impacts of domestic coal use in China. Proc Natl Acad Sci U S A 1999, 96:3427-343I.

II. Zhang J, Smith KR: Emissions of Carbonyl Compounds from Various Cookstoves in China. Environ Sci Technol 1999, 33:23II-2320.

12. Yang G, Fan L, Tan J, Qi G, Zhang Y, Samet JM, Taylor CE, Becker K, $\mathrm{Xu}$ J: Smoking in China: findings of the 1996 National Prevalence Survey. JAMA 1999, 282: I247-1253.

13. Cook DG, Strachan DP: Health effects of passive smoking. 3. Parental smoking and prevalence of respiratory symptoms and asthma in school age children. Thorax 1997, 52:108I-1094.

14. Jaakkola JJ, Jaakkola MS: Effects of environmental tobacco smoke on the respiratory health of children. Scand J Work Environ Health 2002, 28 Suppl 2:7I-83.

15. Lai CK, Chan JK, Chan A, Wong G, Ho A, Choy D, Lau J, Leung R: Comparison of the ISAAC video questionnaire (AVQ3.0) with the ISAAC written questionnaire for estimating asthma associated with bronchial hyperreactivity. Clin Exp Allergy 1997, 27:540-545

16. Zhang JJ, Hu W, Wei F, Wu G, Korn LR, Chapman RS: Children's respiratory morbidity prevalence in relation to air pollution in four Chinese cities. Environ Health Perspect 2002, I I 0:961-967.

17. Bland JM, Altman DG: Statistics notes. The odds ratio. BMJ 2000, 320:1468.

18. Altman DG, Deeks JJ, Sackett DL: Odds ratios should be avoided when events are common. $B M J 1998,317: 1318$.

19. Zocchetti C, Consonni D, Bertazzi PA: Relationship between prevalence rate ratios and odds ratios in cross-sectional studies. Int J Epidemiol 1997, 26:220-223.

20. Skov T, Deddens J, Petersen MR, Endahl L: Prevalence proportion ratios: estimation and hypothesis testing. Int J Epidemiol 1998, 27:91-95.

21. Health effects of outdoor air pollution. Committee of the Environmental and Occupational Health Assembly of the American Thoracic Society. Am J Respir Crit Care Med 1996, 153:3-50.

22. MacNee W, Donaldson K: Exacerbations of COPD: environmental mechanisms. Chest 2000, I 17 Suppl 2:390S-397S.

23. Qian Z, Zhang J, Korn LR, Wei F, Chapman RS: Factor analysis of household factors: are they associated with respiratory conditions in Chinese children? Int J Epidemiol 2004, 33:582-588.

24. Shen S, Qin Y, Cao Z, Shang J, Liu Y, Yang X, Deng Y, Huang J, Fu Z, Song $X$ : Indoor air pollution and pulmonary function in children. Biomed Environ Sci 1992, 5:136-14|.

25. Zheng T, Niu S, Lu B, Fan X, Sun F, Wang J, Zhang Y, Zhang B, Owens $P$, Hao L, Li Y, Leaderer B: Childhood asthma in Beijing, China: a population-based case-control study. Am J Epidemiol 2002, 156:977-983.

26. Duhme H, Weiland SK, Rudolph P, Wienke A, Kramer A, Keil U: Asthma and allergies among children in West and East Germany: a comparison between Munster and Greifswald using the ISAAC phase I protocol. International Study of Asthma and Allergies in Childhood. Eur Respir J 1998, I I:840-847.

27. von Mutius E, Illi S, Nicolai T, Martinez FD: Relation of indoor heating with asthma, allergic sensitisation, and bronchial responsiveness: survey of children in south Bavaria. BMJ 1996, 3 I 2: I448-1450.

28. Cook DG, Strachan DP: Health effects of passive smoking- I0: Summary of effects of parental smoking on the respiratory health of children and implications for research. Thorax 1999, 54:357-366.

29. Mannino DM, Moorman JE, Kingsley B, Rose D, Repace J: Health effects related to environmental tobacco smoke exposure in children in the United States: data from the Third National 
Health and Nutrition Examination Survey. Arch Pediatr Adolesc Med 200I, 155:36-4I.

30. U.S. Environmental Protection Agency: Respiratory Health Effects of Passive Smoking: Lung Cancer and Other Disorders. Washington, DC; 1992.

31. U.S. Department of Health and Human Services, Public Health Service, Office on Smoking and Health: The health consequences of involuntary smoking: A report of the Surgeon General. Rockville, Maryland; 1986.

32. London SJ, James GW, Avol E, Rappaport EB, Peters JM: Family history and the risk of early-onset persistent, early-onset transient, and late-onset asthma. Epidemiology 200 I, I 2:577-583.

33. Morgan WJ: Maternal smoking and infant lung function. Further evidence for an in utero effect. Am J Respir Crit Care Med 1998, I 58:689-690.

34. Joad JP, Munch PA, Bric JM, Evans SJ, Pinkerton KE, Chen CY, Bonham AC: Passive smoke effects on cough and airways in young guinea pigs: role of brainstem substance P. Am J Respir Crit Care Med 2004, 169:499-504.

35. Venners SA, Wang X, Chen C, Wang B, Ni J, Jin Y, Yang J, Fang Z, Weiss ST, $X u$ X: Exposure-response relationship between paternal smoking and children's pulmonary function. $\mathrm{Am} J$ Respir Crit Care Med 200I, 164:973-976.

36. Jaakkola JJ, Nafstad P, Magnus P: Environmental tobacco smoke, parental atopy, and childhood asthma. Environ Health Perspect 200I, 109:579-582.

37. The International Study of Asthma and Allergies in Childhood (ISAAC) Steering Committee: Worldwide variations in the prevalence of asthma symptoms: the International Study of Asthma and Allergies in Childhood (ISAAC). Eur Respir J 1998, 12:315-335.

38. The International Study of Asthma and Allergies in Childhood (ISAAC) Steering Committee: Worldwide variation in prevalence of symptoms of asthma, allergic rhinoconjunctivitis, and atopic eczema: ISAAC. Lancet 1998, 35 I: I225-1232.

39. Withers NJ, Low L, Holgate ST, Clough JB: The natural history of respiratory symptoms in a cohort of adolescents. Am J Respir Crit Care Med 1998, 158:352-357.

40. Øie L, Nafstad P, Botten G, Magnus P, Jaakkola JK: Ventilation in homes and bronchial obstruction in young children. Epidemiology 1999, 10:294-299.

4I. IEH: Airborne particles: Exposures in the home and Health Effects. Leicester, UK: MCR The Institute for Environment and Health; 2000.

42. Britton J: Symptoms and objective measures to define the asthma phenotype. Clin Exp Allergy 1998, 28 SuppI I:2-7.

43. Sunyer J, Basagaña X, Burney P, Anto JM: International assessment of the internal consistency of respiratory symptoms. European Community Respiratory Health Study (ECRHS). Am J Respir Crit Care Med 2000, I 62:930-935.

44. Leung R, Ho P: Asthma, allergy, and atopy in three south-east Asian populations. Thorax 1994, 49: I 205-1210.

45. Leung R, Jenkins M: Asthma, allergy and atopy in southern Chinese school students. Clin Exp Allergy 1994, 24:353-358.

46. Lam TH, Chung SF, Betson CL, Wong CM, Hedley AJ: Respiratory symptoms due to active and passive smoking in junior secondary school students in Hong Kong. Int J Epidemiol 1998, 27:4I-48.

47. Burke JM, Zufall MJ, Özkaynak $\mathrm{H}$ : A population exposure model for particulate matter: case study results for PM(2.5) in Philadelphia, PA. J Expo Anal Environ Epidemiol 200 I, I I:470-489.

48. Qian Z, Zhang J, Wei F, Wilson WE, Chapman RS: Long-term ambient air pollution levels in four Chinese cities: inter-city and intra-city concentration gradients for epidemiological studies. J Expo Anal Environ Epidemiol 200 I, I I:34I-35I.

49. Gong YL, Koplan JP, Feng W, Chen CH, Zheng P, Harris JR: Cigarette smoking in China. Prevalence, characteristics, and attitudes in Minhang District. JAMA 1995, 274: I232-I234.

\section{Publish with Bio Med Central and every} scientist can read your work free of charge

"BioMed Central will be the most significant development for disseminating the results of biomedical research in our lifetime. "

Sir Paul Nurse, Cancer Research UK

Your research papers will be:

- available free of charge to the entire biomedical community

- peer reviewed and published immediately upon acceptance

- cited in PubMed and archived on PubMed Central

- yours - you keep the copyright

Submit your manuscript here:

http://www.biomedcentral.com/info/publishing_adv.asp
BiolMedcentral 